\title{
PREDICTION OF CHLORIDE INGRESS IN STEEL FIBRE REINFORCED CONCRETE UNDER BENDING LOAD
}

\author{
${ }^{\#}$ QIANNAN WANG*, WEI SUN****, LIPING GUO****, CHUNPING GU***, JINYU ZONG* \\ *School of Materials Science \& Engineering, Southeast University, Nanjing 211189, China \\ **Jiangsu Key Laboratory of Construction Materials, Nanjing 211189, China \\ ***College of Civil Engineering and Architecture, Zhejiang University of Technology, Hangzhou 310014, China \\ ${ }^{\#}$ E-mail: wqnseu@163.com
}

Submitted July 26, 2017; accepted October 20, 2017

\begin{abstract}
Keywords: Steel fibre reinforced concrete, Chloride, Time-dependent diffusion coefficient, Corrosion initiation, Stress
Chloride induced corrosion is an important reason for the deterioration of reinforced concrete structures. The chloride transport properties of steel fibre reinforced concrete (SFRC) coupled with and without bending load (stress level of 0.5) were investigated through bulk diffusion test. A prediction model for chloride ingress in SFRC under bending load was established based on the Fick's second law. The time-dependent chloride diffusion coefficient was discussed and calculated. Apparent chloride diffusion coefficient was used to predict the corrosion initiation of SFRC structures. The experimental results showed that SFRC had better chloride resistance than plain concrete, especially when specimens were under bending load. The chloride diffusion coefficient of SFRC under tension was $30 \sim 38 \%$ lower than that of plain concrete. For unstressed concrete, the calculated corrosion initiation of SFRC was 6 40\% longer compared with plain concrete. For concrete under bending load, the corrosion initiation of SFRC was $2.2 \sim 3.6$ times of that for plain concrete, varying with fibres dosage and cover thickness.
\end{abstract}

\section{INTRODUCTION}

The addition of steel fibre significantly improves many engineering properties of mortar and concrete, notably toughness $[1,2]$. Meanwhile, steel fibre reinforced concrete (SFRC) has high durability due to its superior resistance to crack initiation and propagation, especially under external load [3,4]. Chloride induced corrosion of steel reinforcement in concrete is probably the most serious durability problem of reinforced concrete (RC) structures $[5,6]$. Some work has been carried out over the past few decades to investigate the chloride transport property of SFRC, and was reviewed in Ref. [7, 8]. Overall, present studies found that SFRC had similar or slightly better performance on chloride resistance compared with plain concrete.

Chloride transport occurs in the porous network of concrete, which comprises both the hydration-induced porosity and cracks. Under an applied load, distributed micro-cracks propagate, coalesce and align themselves to produce macro-cracks. The presence of these defects and cracks creates easy access routes for chloride ingress, resulting in early steel corrosion in concrete [9]. Therefore, the study of the chloride transport in concrete under external load is of great significance for designing concrete structures and for achieving greater durability. However, research on transport properties of fibre reinforced concrete (FRC) under external load was mostly focused on permeability [10-13]. Only a few studies have evaluated chloride resistance of FRC specimens under loading [14-16]. Antoni et al. [16] found that for both plain concrete and polypropylene FRC specimens under compression, the chloride resistance decreased at low stress levels and increased at high stress levels. While under the same compressive stress level, the chloride resistance of FRC was a lot better than plain concrete. They also observed a greater chloride resistance of FRC when the specimens were under tensile stress [14]. Limited work has been performed to investigate the chloride diffusion in SFRC structures under load. To the authors' knowledge, there is no present study on the prediction of chloride ingress in SFRC under bending load.

Even though SFRC has been used in broad applications for the past several decades, the relatively high cost of SFRC compared with plain concrete still restricts its application to a large extent. Therefore, proving the high durability and long service life of SFRC can promote its application, and has great significance for the development of SFRC. In this paper, chloride bulk diffusion tests were carried out on plain concrete and SFRC specimens with and without bending load. The chloride resistances of different concrete specimens were compared and discussed. Based on the test results, the time-dependent apparent chloride diffusion coefficients were calculated, and the corrosion initiations of plain concrete and SFRC under bending load were predicted. 
Wang Q., Sun W., Guo L., Gu Ch., Zong J.

\section{THEORETICAL}

Chloride diffusion theory

Fick's second law of diffusion

The mechanism of chloride transport into concrete structures is a rather complicated process. Hooton [17] pointed out there were at least six transport mechanisms for chloride penetrating into concrete: adsorption, diffusion, binding, penetration, capillary suction and dispersion, etc. For simplicity's sake, all kinds of chloride transport mechanisms in concrete are generally regarded as 'apparent diffusion'. The diffusion equation based on Fick's second law is a most convenient mathematical model to describe the non-steady diffusion processes of chloride ingress in a concrete structure. By assuming the chloride diffusion coefficient is constant, the well-known analytical solution of the Fick's second law of diffusion is

$$
C(x, t)=C_{s}\left(1-\operatorname{erf} \frac{x}{2 \sqrt{D t}}\right)
$$

where $C(x, t)$ is chloride concentration at depth $x$ and immersion time $t, C_{s}$ is chloride concentration at the surface, $x$ is the penetration depth, $t$ is the immersion time, and $D$ is chloride diffusion coefficient.

\section{Time-dependent chloride diffusion coefficient}

The chloride diffusion coefficient of concrete is not constant but decreases over time due to the continuous hydration [18, 19]. In 1992, Tang and Nilsson [20] found that the measured diffusion coefficient in young concrete dramatically decreased with age based on their rapid diffusivity test, and they proposed the mathematical expression for a time-dependent chloride diffusion coefficient based on Crank's mathematics of diffusion:

$$
D(t)=a \cdot t^{-n}
$$

where $D(t)$ is the time-dependent diffusion coefficient, $t$ is the concrete age, and $a$ and $n$ are constants, with $n$ normally being referred to as the age factor. If the chloride diffusion coefficient $D_{0}$ at the age of $t_{0}$ is known, Equation 2 can be rewritten as

$$
D(t)=D_{0} \cdot t_{0}^{n} \cdot t^{-n}=D_{0} \cdot\left(t / t_{0}\right)^{-n}
$$

The hydration rate of concrete gradually decreases and comes to a halt with time. Life-365 (a software designed for estimating the service life and life-cycle costs of concrete and corrosion protection systems) Manual [21] suggested that Equation 3 should be applied

\begin{tabular}{|c|c|c|c|c|c|}
\hline Author & Type of concrete & $\mathrm{w} / \mathrm{c}$ & $\mathrm{w} / \mathrm{b}$ & $n$ & Empirical equation for $n$ \\
\hline Tang [20] & $\mathrm{OPC}$ & $\begin{array}{l}0.70 \\
0.32\end{array}$ & $\begin{array}{l}0.70 \\
0.32\end{array}$ & $\begin{array}{l}0.25 \\
0.32\end{array}$ & $n=1.152(w / c)^{-0.6}$ \\
\hline Chalee [22] & $\begin{array}{l}\text { OPC } \\
\text { OPC } \\
\text { OPC } \\
\text { Concrete with } 25 \% \text { FA } \\
\text { Concrete with } 35 \% \text { FA } \\
\end{array}$ & $\begin{array}{l}0.45 \\
0.55 \\
0.65 \\
0.60 \\
0.69\end{array}$ & $\begin{array}{l}0.45 \\
0.55 \\
0.65 \\
0.45 \\
0.45 \\
\end{array}$ & $\begin{array}{l}0.756 \\
0.739 \\
0.709 \\
0.831 \\
0.839\end{array}$ & $\begin{array}{l}n=[-0.0015(W / B)+0.0034] \\
. \% \mathrm{FA}+[-0.175(W / B)+0.84]\end{array}$ \\
\hline Mangat [23] & $\begin{array}{l}\text { OPC } \\
\text { OPC } \\
\text { Concrete with } 25 \% \text { FA } \\
\text { Concrete with } 60 \% \text { slag } \\
\text { Concrete with } 15 \% \text { microsilica }\end{array}$ & $\begin{array}{l}0.58 \\
0.45 \\
0.77 \\
1.45 \\
0.68\end{array}$ & $\begin{array}{l}0.58 \\
0.45 \\
0.58 \\
0.58 \\
0.58 \\
\end{array}$ & $\begin{array}{l}0.53 \\
0.47 \\
1.34 \\
1.23 \\
1.13 \\
\end{array}$ & $n=2.5(W / C)^{-0.6}$ \\
\hline Boddy [24] & $\begin{array}{l}\text { OPC } \\
\text { Concrete with } 8 \% \mathrm{HRM}^{*} \\
\text { Concrete with } 12 \% \mathrm{HRM} \\
\text { OPC } \\
\text { Concrete with } 8 \% \mathrm{HRM} \\
\text { Concrete with } 12 \% \mathrm{HRM}\end{array}$ & $\begin{array}{l}0.40 \\
0.43 \\
0.45 \\
0.30 \\
0.33 \\
0.34\end{array}$ & $\begin{array}{l}0.40 \\
0.40 \\
0.40 \\
0.30 \\
0.30 \\
0.30 \\
\end{array}$ & $\begin{array}{l}0.43 \\
0.44 \\
0.50 \\
0.27 \\
0.38 \\
0.46 \\
\end{array}$ & - \\
\hline Audenaert [18] & Concrete with $40 \%$ limestone & $\begin{array}{l}0.40 \\
0.46 \\
0.55 \\
0.60\end{array}$ & $\begin{array}{l}0.24 \\
0.28 \\
0.33 \\
0.36\end{array}$ & $\begin{array}{l}0.40 \\
0.28 \\
0.22 \\
0.22\end{array}$ & $n=-0.0318 \phi_{\text {cap }}+0.5544$ \\
\hline Thomas [25] & $\begin{array}{l}\text { OPC } \\
\text { Concrete with } 30 \% \text { FA } \\
\text { Concrete with } 70 \% \text { slag } \\
\end{array}$ & $\begin{array}{l}0.66 \\
0.75 \\
0.61 \\
\end{array}$ & $\begin{array}{l}0.66 \\
0.54 \\
0.48 \\
\end{array}$ & $\begin{array}{l}0.10 \\
0.70 \\
1.20 \\
\end{array}$ & - \\
\hline Stanish [26] & $\begin{array}{l}\text { OPC } \\
\text { Concrete with } 25 \% \text { FA } \\
\text { Concrete with } 56 \% \text { FA }\end{array}$ & $\begin{array}{l}0.50 \\
0.67 \\
1.14\end{array}$ & $\begin{array}{l}0.50 \\
0.50 \\
0.50\end{array}$ & $\begin{array}{l}0.32 \\
0.66 \\
0.79\end{array}$ & - \\
\hline
\end{tabular}
to concrete younger than 25 years and after 25 years D

Table 1. Values of age factor $n$. 
holds the constant at the 25 -year value. The analytical solution of the Fick's second law can only be derived under the assumption that the chloride coefficient is constant. Therefore, mathematical treatment needs to be done to the time-dependent chloride diffusion coefficient to get an average coefficient, which is defined as apparent chloride diffusion coefficient as given in Equation 4

$$
\begin{aligned}
& D_{a}=\frac{\int D(\mathrm{t}) d t}{t}= \\
& =D_{0} /(1-n) \cdot\left[\left(1+t_{s} / t_{d}\right)^{1-n}-\left(t_{s} / t_{d}\right)^{1-n}\right] \cdot\left(t_{0} / t_{d}\right)^{n}
\end{aligned}
$$

where $D_{a}$ is the apparent chloride diffusion coefficient, $t_{s}$ and $t_{d}$ are the age when concrete starts to be exposed to chlorides and exposure duration, respectively.

Strictly speaking, the apparent diffusion coefficient $D_{a}$ instead of $D(t)$ can be used in the analytical solution of Fick's second law and Equation 1 is rewritten as

$$
C(x, t)=C_{s}\left(1-\operatorname{erf} \frac{x}{2 \sqrt{D_{a} t}}\right)
$$

\section{Age factor $n$}

The age factor $n$ is an important parameter for determining the time-dependent chloride diffusion coefficient. However, there are different opinions about the effect of concrete composition on age factor $n$. Table 1 gives some values of $n$ for different concrete. It is obvious that both water/cement $(w / c)$ ratio and admixtures have an important impact on $n$. The use of admixtures such as fly ash (FA) and slag would increase the age factor without any doubts. That means using fly ash and slag contributes to further decrease of diffusion coefficient with time. However, there are quite different conclusions when it comes to w/c ratio. For ordinary Portland concrete (OPC), a lower $n$ with a higher w/c ratio was observed by Tang [20] and Chalee [22]. However, Mangat [23] and Boddy [24] found that increasing the $w / c$ ratio lead to a higher $n$. For concrete containing admixtures, the effect of w/c ratio on $n$ is not as clear as the effect of $w / b$ ratio. Age factor $n$ declined with the increase of $w / b$ ratio in Ref. $[18,22,25]$. The disagreement on the effect of $w / c$ ratio may be caused by different test methods and conditions. Besides, $n$ may be affected by some other factors hence the change of $n$ in different concrete might involve the effects of many factors rather than just $w / c$ ratio. Further research is still needed for the determination of $n$ in the future.

\section{Corrosion initiation prediction}

The deterioration process of RC structures caused by chloride ingress consists of two periods: initiation and propagation [27]. The length of the initiation period can be estimated from the time required for chlorides to reach rebar surfaces and trigger active corrosion. The propagation period can be taken as the time elapse until repair becomes mandatory. In this paper, the corrosion initiation period is predicted.
Taking the cover thickness of concrete structure as the depth $x$ in Equation 5, the time needed for chlorides to reach the critical concentration at depth $x$ can be regarded as corrosion initiation period. If the critical chloride concentration $C_{c r}$, the surface chloride concentration $C_{s}$ and the apparent chloride diffusion coefficient $D_{a}$ are determined, the corrosion initiation can be predicted with Equation 5.

Glass and Buenfeld [28] suggested that the critical chloride concentration $C_{c r}$ could be $0.4 \%$ (by mass of cement) for buildings exposed to a temperate European climate and $0.2 \%$ for structures exposed to a more aggressive environment. The range of $0.2 \sim 0.4 \%$ by mass of cement is equivalent to a range of $0.03 \sim 0.07 \%$ by mass of concrete (for typical concretes with cement contents in the range of 350 to $400 \mathrm{~kg} \cdot \mathrm{m}^{-3}$ ). Consequently, a value of $C_{c r}=0.05 \%$ (by mass of concrete) was adopted here. Life-365 model [21] assumed a constant value of $0.8 \%$ (by mass of concrete) for surface chloride concentration $C_{s}$ of concrete structures in marine splash zone. The value of $C_{s}$ in this study was set to be $0.8 \%$ as well. As for the chloride diffusion coefficient, $D_{a}$ was firstly determined through experiment. Consequently, the chloride diffusion coefficient $D_{0}$ at time $t_{0}$ was calculated with Equation 4. With a pair of known $D_{0}$ at time $t_{0}$, the corrosion initiation can be predicted by substitute Equation 4 into Equation 5.

\section{EXPERIMENTAL}

\section{Materials and mixture proportions}

The materials used in this study were Portland cement; fly ash; natural sand with a maximum grain size of $4.75 \mathrm{~mm}$; gravel with size ranging from 5 to $20 \mathrm{~mm}$; water; and hooked steel fibres with a length of $35 \mathrm{~mm}$ and a diameter of $0.55 \mathrm{~mm}$. The tensile strength of steel fibres was $1345 \mathrm{MPa}$ and the elastic modulus was $210 \mathrm{GPa}$. The chemical compositions and physical properties of cement and fly ash are listed in Table 2 .

Mixture proportions of the concrete are given in Table 3. C50 was plain concrete without steel fibres. SFRC-1 and SFRC-1.5 were SFRC with steel fibres of $1 \%$ and $1.5 \%$ in volume fraction, respectively. Fly ash was used to replace $30 \%$ of cement. The water/binder ratio of the concretes was 0.35 , which was relatively low. As a result, the addition of steel fibres would lead to a loss in workability, which is a very important index of concrete in practical application. Compared with plain concrete, the loss in workability of SFRC could limit its application to a certain extent. Based on this consideration, the SFRCs in this study were designed to achieve a similar workability with plain concrete. As the volume fraction of steel fibres increased, the amount of gravel was reduced and the amount of mortar was increased to accommodate the increased surface area of steel fibres. The measured slumps of all the fresh mixtures were 
within $200 \pm 10 \mathrm{~mm}$. Roque et al. [29] and Teruzzi et al. [30, 31] adopted a similar mixture design approach when studying the durability of SFRC and effects of steel fibres. The compressive strengths of C50, SFRC-1 and SFRC-1.5 at 28 days were $60.5 \mathrm{MPa}, 60.8 \mathrm{MPa}$ and $61.6 \mathrm{MPa}$, respectively. Clearly, the compressive strength of C50 and SFRC were very close and in the same strength grade.

The mixtures were cast into $500 \times 130 \times 100 \mathrm{~mm}^{3}$ moulds for flexural and chloride bulk diffusion tests. After 24 hours curing in moulds, the specimens were demoulded and cured in standard conditions $\left(20^{\circ} \mathrm{C}\right.$, $\mathrm{RH}>95 \%$ ) until 90 days.

\section{Bulk diffusion test}

A modified non-steady state diffusion test, based on NT Build 443 [32], was used to estimate the resistance against chloride penetration into plain concrete and SFRC. After 90 days standard curing, the specimens were surface dried and coated with epoxy painted on all surfaces except one exposed surface. For the specimens under load, bending load was applied through a stainless steel loading device (Figure 1). The stress was applied and controlled through adjusting the deformation of the springs. The exposed surface of the stressed specimen was placed on the tensile side. Specimens with and without bending load were submerged in a $3.5 \%$ sodium chloride $(\mathrm{NaCl})$ solution. The stressed specimens were immersed in the $\mathrm{NaCl}$ solution with the loading device so that the bending load was applied to the specimens throughout the diffusion test.

Due to the varying flexural strengths of concretes, it is widely adopted that the stress level (ratio of the applied stress to the ultimate strength), instead of bending load, set to be identical when studying the effect of stress on chloride resistance of concrete. The studied bending load was set at a stress level of 0.5 and the detailed information about the bending load is given in Table 4 .

After 60 days, 90 days and 150 days immersion, respectively, specimens were taken out to determine the chloride contents at varying depths from the exposed

Table 2. Chemical compositions and physical properties of cement and fly ash.

\begin{tabular}{|c|c|c|c|c|c|c|c|c|}
\hline \multicolumn{9}{|c|}{ Chemical compositions (\% by weight) } \\
\hline & $\mathrm{SiO}_{2}$ & $\mathrm{Al}_{2} \mathrm{O}_{3}$ & $\mathrm{Fe}_{2} \mathrm{O}_{3}$ & $\mathrm{CaO}$ & $\mathrm{MgO}$ & $\mathrm{SO}_{3}$ & $\mathrm{Na}_{2} \mathrm{O}+\mathrm{K}_{2} \mathrm{O}$ & LOI* \\
\hline Cement & 20.40 & 4.70 & 3.38 & 64.70 & 0.87 & 1.88 & 0.82 & 3.24 \\
\hline Fly ash & 54.88 & 26.89 & 6.49 & 4.77 & 1.31 & 1.16 & 1.93 & 3.10 \\
\hline \multicolumn{9}{|c|}{ Physical properties } \\
\hline & \multicolumn{3}{|c|}{ Specific gravity } & \multicolumn{3}{|c|}{ Specific surface area $\left(\mathrm{m}^{2} \cdot \mathrm{kg}^{-1}\right)$} & & \\
\hline Cement & \multicolumn{3}{|c|}{3.15} & \multicolumn{3}{|c|}{362} & & \\
\hline Fly ash & \multicolumn{3}{|c|}{2.24} & \multicolumn{3}{|c|}{454} & & \\
\hline
\end{tabular}

*LOI: Loss on ignition

Table 3. Mixture proportions.

\begin{tabular}{lccccccc}
\hline & $\begin{array}{c}\text { Cement } \\
\left(\mathrm{kg} \cdot \mathrm{m}^{-3}\right)\end{array}$ & $\begin{array}{c}\text { Fly ash } \\
\left(\mathrm{kg} \cdot \mathrm{m}^{-3}\right)\end{array}$ & $\begin{array}{c}\text { Sand } \\
\left(\mathrm{kg} \cdot \mathrm{m}^{-3}\right)\end{array}$ & $\begin{array}{c}\text { Gravel } \\
\left(\mathrm{kg} \cdot \mathrm{m}^{-3}\right)\end{array}$ & $\begin{array}{c}\text { Water } \\
\left(\mathrm{kg} \cdot \mathrm{m}^{-3}\right)\end{array}$ & $\begin{array}{c}w / b^{*} \\
\mathrm{ratio}\end{array}$ & $\begin{array}{c}V_{f} \\
(\%)\end{array}$ \\
\hline C50 & 315 & 135 & 663 & 1179 & 158 & 0.35 & - \\
SFRC-1 & 370 & 158 & 779 & 917 & 185 & 0.35 & 1 \\
SFRC-1.5 & 379 & 163 & 799 & 834 & 189 & 0.35 & 1.5 \\
\hline
\end{tabular}

*w/b: water/binder
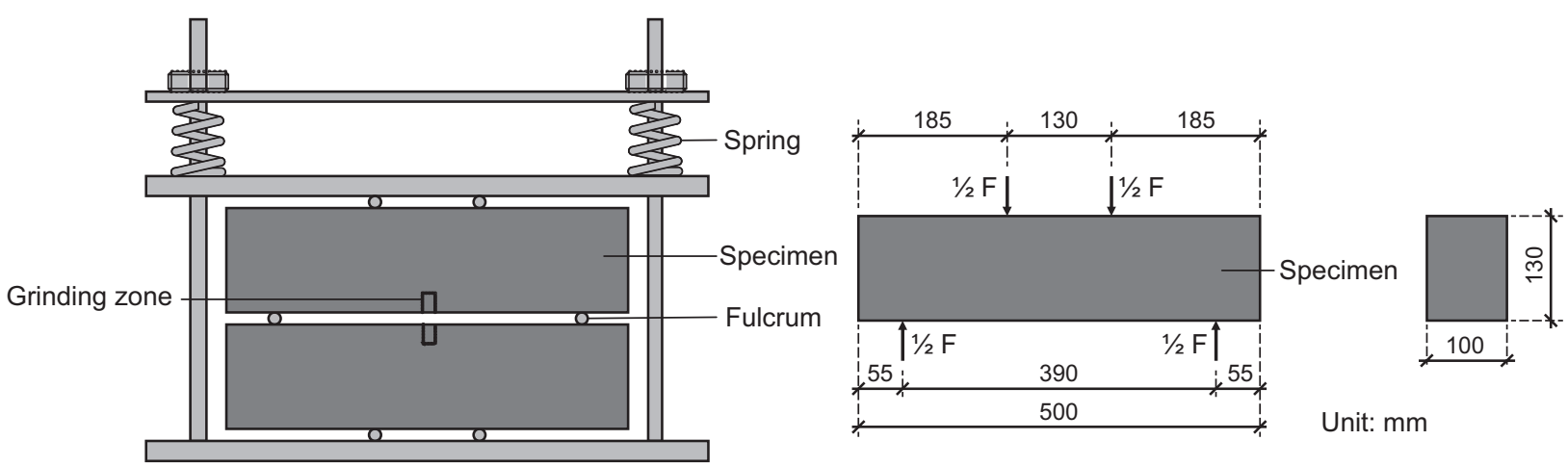

Figure 1. Loading device for the chloride bulk diffusion test. 
surface. Thin layers were ground off parallel to the exposed face of the specimen with a grinding machine. The water-soluble chloride, namely free chloride of the layers was determined through titration according to JTJ 270-98 [33]. There were compressive stress and tensile stress in specimens under bending load, which both had effects on the chloride transport properties of concrete. Considering the rebars were usually placed in the tensile zones, the chloride concentration near the tensile surface was measured for the stressed specimens and the grinding zone was the centre of the tensile surface, as shown in Figure 1. By using the least squares non-linear regression, the measured chloride profiles were fitted to the solution of Fick's second law of diffusion and the apparent chloride diffusion coefficient was determined.

Table 4. Flexural strength and bending load (at a stress level of 0.5$)$ at 90 days.

\begin{tabular}{lccc}
\hline & C50 & SFRC-1 & SFRC-1.5 \\
\hline Flexural strength (MPa) & 5.87 & 8.69 & 9.16 \\
\hline $\begin{array}{l}\text { Bending load in bulk } \\
\text { diffusion tests }(\mathrm{kN})\end{array}$ & 13.7 & 18.9 & 19.8 \\
\hline
\end{tabular}

\section{RESULTS AND DISCUSSION}

\section{Chloride diffusion properties}

Based on Equation 5, the apparent chloride diffusion coefficient $D_{a}$ was found by iteration. Results of $D_{a}$ for different immersion times are given in Table 5 .

As shown in Table 3, the apparent chloride diffusion coefficients of both plain concrete and SFRC specimens were not constant and decreased over time resulting from the refinement of the pore structure, which should be taken into consideration when used for corrosion initiation prediction.

For the unstressed specimens, the chloride resistance of SFRC specimens was slightly better than plain concrete specimens. After 150 days immersion without load, $D_{a}$ of SFRC 50-1 was $1 \%$ lower than C 50 , and $D_{a}$ of SFRC- 1.5 was $13 \%$ lower than C50. The improvement in the chloride resistance of concrete due to steel fibres in this study could be contributed to several factors: (1) The steel fibre could restrain the shrinkage of concrete and hence reduced the quantity and width of the microcracks; (2) Compared with plain concrete, SFRC had more amounts of cement and fly ash. As a consequence, there were more chlorides bound with the hydrates and hence retarded the chloride transport process [34]. As reviewed in [8], the effects of steel fibres on the chloride resistance of concrete are still open issues and clearly need further study. Overall, the changes in chloride resistance of concrete due to adding steel fibres are insignificant, no matter the matrixes of concretes are identical or properly adjusted (reducing the amount of gravel as the fibre volume fraction increased) as in this study.

On the other hand, the difference in $D_{a}$ for plain concrete and SFRC specimens under tensile stress was quite significant. Since the flexural strength of concrete was greatly improved by adding steel fibres, the bending load applied on C50 specimens was actually much lower than SFRC specimens under the same stress level of 0.5. Even so, after 150 days immersion with bending load, $D_{a}$ of SFRC50-1 was $29 \%$ lower and $D_{a}$ of SFRC-1.5 was $38 \%$ lower, compared with $D_{a}$ of C50. Due to the superior resistance of steel fibres to crack initiation and propagation, the addition of fibres lead to a change in the crack profile whereby, instead of a few large cracks, a multitude of closely spaced microcracks form [35]. The transport properties of concrete are very sensitive to the crack widths. The reduction in crack widths by adding steel fibres would significantly improve the chloride resistance of concrete under stress.

\section{Chloride diffusion coefficient $\mathrm{D}_{0}$}

The age factor $n$ needed to be determined before calculating the chloride diffusion coefficient $D_{0}$. However, its determination requires lots of data on chloride diffusion coefficients and is very time-consuming. The concretes in this study contained $30 \%$ fly ash as cement replacement material. As mentioned above, the addition of fly ash would increase the value of $n$ compared with OPC. The age factor $n$ for concrete containing fly ash in Table 1 is in the range of $0.66 \sim 1.34$, varying with fly ash dosage and water/binder ratio. Besides, Bamforth [36] suggested the age factor for concrete with $30 \sim 50 \%$ fly ash was 0.70 . Duracrete [37] suggested an age factor of 0.69 for concrete containing fly ash in a submerged environment. Apparently, the value of 0.69 for $n$ is relatively conservative for concrete containing fly ash. Moreover, considering the specimens were submerged in $\mathrm{NaCl}$ solution as well during the chloride diffusion tests, the value of 0.69 for $n$ was adopted in this paper. Consequently, the following corrosion initiation predicted with this age factor $(0.69)$ was only applicable for concrete in a submerged environment.

Table 5. Best-fit apparent chloride diffusion coefficients.

\begin{tabular}{|c|c|c|c|c|c|c|c|c|c|c|}
\hline \multirow{2}{*}{\multicolumn{2}{|c|}{$\begin{array}{l}\text { Mixture ID } \\
\text { Immersion time (days) }\end{array}$}} & \multicolumn{3}{|c|}{$\mathrm{C} 50$} & \multicolumn{3}{|c|}{ SFRC-1 } & \multicolumn{3}{|c|}{ SFRC-1.5 } \\
\hline & & 60 & 90 & 150 & 60 & 90 & 150 & 60 & 90 & 150 \\
\hline \multirow{2}{*}{$\mathrm{Da}\left(\times 10^{-12} \mathrm{~m}^{2} \cdot \mathrm{s}^{-1}\right)$} & Unstressed & 2.18 & 2.05 & 1.81 & 2.11 & 1.93 & 1.79 & 1.97 & 1.81 & 1.57 \\
\hline & Tensile zone & 3.32 & 3.07 & 2.71 & 2.24 & 2.21 & 1.92 & 2.16 & 1.86 & 1.68 \\
\hline
\end{tabular}

Ceramics - Silikáty 62 (1) 59-66 (2018) 
Wang Q., Sun W., Guo L., Gu Ch., Zong J.

Table 6. Results of chloride diffusion coefficient $D_{0}\left(\times 10^{-12} \mathrm{~m}^{2} \cdot \mathrm{s}^{-1}\right)\left(t_{0}=60 \mathrm{~d}\right)$.

\begin{tabular}{|c|c|c|c|c|c|c|}
\hline \multirow{2}{*}{$\begin{array}{l}\text { Immersion time } \\
\text { (days) }\end{array}$} & \multicolumn{2}{|c|}{$\mathrm{C} 50$} & \multicolumn{2}{|c|}{ SFRC-1 } & \multicolumn{2}{|c|}{ SFRC-1.5 } \\
\hline & Unstressed & Under tension & Unstressed & Under tension & Unstressed & Under tension \\
\hline 60 & 3.47 & 5.29 & 3.36 & 3.57 & 3.14 & 3.44 \\
\hline 90 & 3.51 & 5.25 & 3.30 & 3.78 & 3.10 & 3.18 \\
\hline 150 & 3.48 & 5.21 & 3.44 & 3.69 & 3.02 & 3.23 \\
\hline Average of $D_{0}$ & 3.49 & 5.25 & 3.37 & 3.68 & 3.08 & 3.28 \\
\hline
\end{tabular}

The chloride diffusion coefficient $D_{0}$ was calculated with Equation 4. The results are shown in Table 6 (given $t_{0}$ was 60 days).

As shown in Table 6, the differences in $D_{0}$ of unstressed concrete specimens were not substantial, which was consistent with the results of $D_{a}$. Compared with unstressed C50 specimen, $D_{0}$ was reduced by $3 \%$ with SFRC-1, and $12 \%$ with SFRC-1.5. When concrete specimens were under bending load, the presence of steel fibres made a significant difference on $D_{0}$. $D_{0}$ of SFRC-1 and SFRC-1.5 were $30 \%$ and $38 \%$ lower than that of $\mathrm{C} 50$, respectively. Besides, the applied bending load raised the chloride diffusion coefficient $D_{0}$ by $50 \%$ for plain concrete C50. While for SFRC, $D_{0}$ of SFRC-1 and SFRC-1.5 were only increased by $9 \%$ and $6 \%$, respectively, due to the bending load. In other words, the effect of bending load on chloride diffusion coefficient was impaired remarkably by steel fibres. This means the application of SFRC could enhance the durability of RC structures exposed to chloride environments and prolong the service life of structures greatly.

\section{Prediction on corrosion initiation}

The corrosion initiation of $\mathrm{RC}$ structures was evaluated based on the solution of Fick's second law (Equation 5). The apparent chloride diffusion coefficient $D_{a}$ was calculated through Equation 4. Given

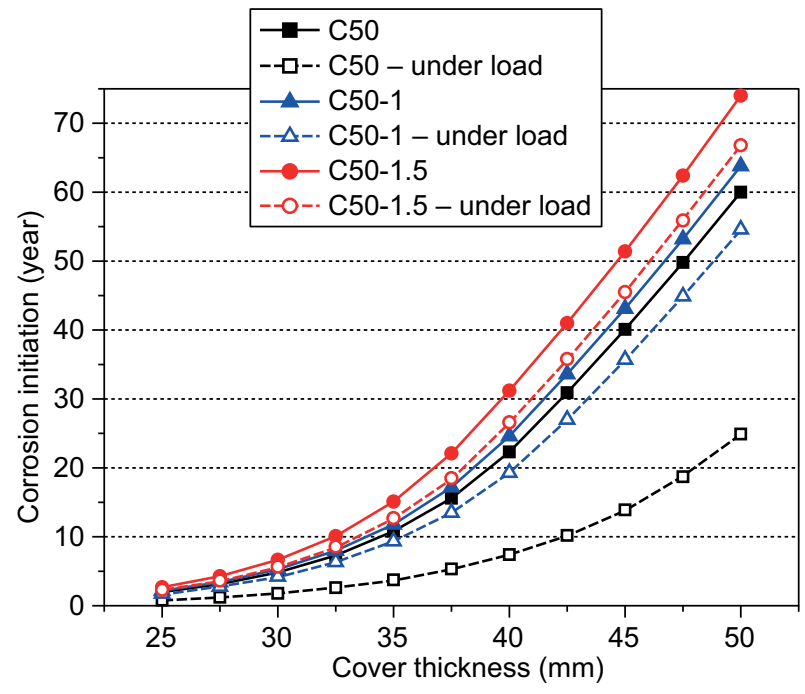

Figure 2. Predicted corrosion initiation of SFRC and plain concrete. concrete was exposed to chloride environment at the age of 14 days, that was $t_{s}=14 \mathrm{~d}$. A common range of $25 \sim 50 \mathrm{~mm}$ for cover thickness was investigated. The corrosion initiations of submerged concrete structures with and without bending load (at a stress level of 0.5 ) were pre-dicted and the results are shown in Figure 2.

As shown in Figure 2, the corrosion initiation got longer as the cover thickness increased. The slopes of the curves grew with the cover thickness as well, which means increasing cover thickness is a simple and effective way to retard the corrosion initiation. For RC structures under no stress, the corrosion initiations of different kinds of concrete cover didn't vary very much, especially between C50 and SFRC-1. For plain concrete $\mathrm{C} 50$, the corrosion initiations were shortened by about $60 \%$ when there was bending load applied. The corresponding decrements for SFRC-1, SFRC-1.5 were $20 \%$ and $13 \%$, respectively. Besides, for RC structures under bending load, the corrosion initiation of plain concrete C50 was only about $1 / 3$ of SFRC with the same cover thickness. This means when RC structures are under external bending load, SFRC could significantly retard the corrosion initiation.

Table 7 lists the ratios of corrosion initiations of SFRC to plain concrete C50. For unstressed concrete, the corrosion initiation of SFRC was $6 \sim 40 \%$ longer compared with plain concrete. For concrete under bending load, the corrosion initiation of SFRC was $2.2 \sim 3.6$ times of that for plain concrete, varying with fibres dosage and cover thickness. It is obvious from Table 7 that the ratios are sensitive to the cover thickness. For a common cover thickness range of $25 \sim 50 \mathrm{~mm}$, SFRC had the most remarkable effect on prolonging the corrosion initiation when the cover thickness is within $35 \sim 40 \mathrm{~mm}$. Take a cover thickness of $35 \mathrm{~mm}$ for example, the corrosion initiation of stressed RC structures was prolonged by $9 \%$ with SFRC-1, and $40 \%$ with SFRC-1.5. Considering the cost of SFRC, its application on unstressed RC structures may be not economic. However, for RC structures

Table 7. Ratios of corrosion initiation.

\begin{tabular}{llcccccc}
\hline \multirow{2}{*}{ Ratio of corrosion initiation } & \multicolumn{6}{c}{ Cover thickness (mm) } \\
\cline { 3 - 8 } & & 25 & 30 & 35 & 40 & 45 & 50 \\
\hline Without & (SFRC-1)/(C50) & 1.09 & 1.09 & 1.09 & 1.10 & 1.07 & 1.06 \\
load & (SFRC-1.5)/(C50) & 1.35 & 1.38 & 1.40 & 1.40 & 1.28 & 1.23 \\
\hline Under ben- & (SFRC-1)/(C50) & 2.17 & 2.26 & 2.60 & 2.60 & 2.57 & 2.19 \\
ding load & (SFRC-1.5)/(C50) & 2.85 & 2.99 & 3.58 & 3.58 & 3.27 & 2.68 \\
\hline
\end{tabular}


under bending load, SFRC-1 can extend the corrosion initiation to 2.6 times, and SFRC-1.5 can extend the corrosion initiation to 3.6 times, compared with plain concrete. Besides, the presence of steel fibres can restrict the cracking in concrete during the propagation period, hence extend the propagation period as well. Overall, the application of SFRC can prolong the service life and reduce the maintenance cost of RC structures in loadcoupled chloride environment. Therefore, SFRC has a lower life-circle cost and is more environment-friendly under some circumstances.

\section{CONCLUSIONS}

To verify the advantages of using SFRC for $\mathrm{RC}$ structures, the bulk chloride diffusion tests were performed on plain concrete and SFRC specimens with and without bending load (at a stress level of 0.5). Based on Fick's second law and its analytical solution, the chloride ingress in submerged SFRC under bending load was predicted. Considering the chloride diffusion coefficient was time-dependent, the apparent diffusion coefficient was introduced and used for corrosion initiation prediction. Based on the results obtained, the following conclusions could be drawn:

- For unstressed concrete, the chloride diffusion coefficient of plain concrete was a bit higher than SFRC, while the difference was not substantial.

- When concrete was under bending load at stress level of 0.5 , the presence of steel fibres greatly reduced the impact of bending load on the chloride diffusion rate. For concrete in tension, $D_{0}$ of SFRC- 1 was $30 \%$ lower, and $D_{0}$ of SFRC-1.5 was $38 \%$ lower, respectively, than that of plain concrete C 50 .

- According to the predicted results, the advantage of using SFRC for RC structures under no load was not obvious. On the other hand, the corrosion initiation of plain concrete was shortened by about $60 \%$ when there was bending load applied. It was reduced by no more than $20 \%$ for SFRC under the same conditions. The using of SFRC could prolong the initiation period of concrete structures to $2.2 \sim 3.6$ times of that for plain concrete, varying with the fibre dosage and cover thickness. Therefore, SFRC can improve the chloride resistance and prolong the service life of concrete structures in severe chloride environment.

\section{Acknowledgements}

This work was supported by a technical research program from NV Bekaert SA of Belgium, the National Natural Science Foundation of China (Grant No. 51378113, 51438003) and a Plan of Six Peak Talents in Jiangsu Province (Grant No. JZ-004), and was partly supported by a National Basic Research Program of China (973 Program with Grant No. 2015CB655102).

\section{REFERENCES}

1. Banthia N., Chokri K., Ohama Y., Mindess S. (1994): Fiber-Reinforced Cement-Based Composites under Tensile Impact. Advanced Cement Based Materials, 1(3), 131-141. doi:10.1016/1065-7355(94)90044-2

2. Gopalaratnam V. S., Shah S. P., Batson G. B., Criswell M. E., Ramakrishnan V., Wecharatana M. (1991): Fracture toughness of fiber reinforced concrete. ACI Materials Journal, 88(4), 339-353. doi: 10.14359/1840

3. Mangat P. S., Gurusamy K. (1987): Chloride Diffusion in Steel Fiber Reinforced Marine Concrete. Cement and Concrete Research, 17(3), 385-396. doi: 10.1016/00088846(87)90002-0

4. Miao C., Mu R., Tian Q., Sun W. (2002): Effect of sulfate solution on the frost resistance of concrete with and without steel fiber reinforcement. Cement and Concrete Research, 32(1), 31-34. doi:10.1016/S0008-8846(01)00624-X

5. Gérard B., Marchand J. (2000): Influence of cracking on the diffusion properties of cement-based materials: Part I: Influence of continuous cracks on the steady-state regime. Cement and Concrete Research, 30(1), 37-43. doi:10.1016/ S0008-8846(99)00201-X

6. Mehta P. K. (1991): Concrete durability-fifty years progress, in: Proceedings of 2nd International Conference on Concrete Durability, Ed. V. M. Malhotra. Montreal, Canada, p.1-31.

7. Gu C., Ye G., Sun W. (2015): A review of the chloride transport properties of cracked concrete: experiments and simulations. Journal of Zhejiang University SCIENCE A, 16(2), 81-92. doi: 10.1631/jzus.A1400247

8. Berrocal C. G., Lundgren K., Löfgren I. (2015): Corrosion of steel bars embedded in fibre reinforced concrete under chloride attack: state of the art. Cement and Concrete Research, 80, 69-85. doi:10.1016/j.cemconres.2015.10.006

9. Banthia N. (1994): Fiber reinforced concrete. ACI SP142ACI, Detroit, MI, 91-119

10. Banthia N., Bhargava A. (2007): Permeability of stressed concrete and role of fiber reinforcement. ACI Materials Journal, 104, 70-76. doi: 10.14359/18497

11. Lawler J. S., Zampini D., Shah S. P. (2002): Permeability of cracked hybrid fiber-reinforced mortar under load. $A C I$ Materials Journal, 99, 379-385. doi: 10.14359/12220

12. Rapoport J., Aldea C. M., Shah S. P., Ankenman B., Karr A. (2002): Permeability of cracked steel fiber-reinforced concrete. Journal of Materials in Civil Engineering, 14, 355-358. doi: 10.1061/(ASCE)0899-1561(2002)14:4(355)

13. Charron J. P., Denarié E., Brühwiler E. (2007): Permeability of ultra high performance fiber reinforced concretes (UHPFRC) under high stresses. Materials \& Structures, 40, 269-277. doi: 10.1617/s11527-006-9105-0

14. Antoni, Horiguchi T., Saeki N. (2003): Influence of stress on chloride penetration into fiber reinforced concrete, in: Proceedings of the Japan Concrete Institute, 25, 779-784.

15. Antoni (2008): Chloride penetration into fiber reinforced concrete under static and cyclic compressive loading. Civil Engineering Dimension, 10, 63-69.

16. Antoni, Horiguchi T., Saeki N. (2004): Performance of fiber reinforced concrete against chloride penetration under loading. Proceedings of the Japan Concrete Institute 26, 921-926.

17. Hooton R. D., McGrath P. F. (1997). Issues related to recent developments in service life specifications for concrete 
structures, in: Proceedings of the $1^{\text {st }}$ RILEM Workshop on Chloride Penetration into Concrete, Ed. L. O. Nilsson and J. P. Olliver. Saint-Remy-Les-Chevreuse, France, pp.388-397. doi: $10.1617 / 2912143454.039$

18. Audenaert K., Yuan Q., De Schutter G. (2010): On the time dependency of the chloride migration coefficient in concrete. Construction and Building Materials, 24, 396402. doi:10.1016/j.conbuildmat.2009.07.003

19. Pack S. W., Jung M. S., Song H. W., Kim S. H., Ann K. Y. (2010): Prediction of time dependent chloride transport in concrete structures exposed to a marine environment. Cement and Concrete Research, 40(2), 302-312. doi:10.1016/j.cemconres.2009.09.023

20. Tang L., Nilsson L. O. (1992): Chloride diffusivity in high strength concrete at different ages. Nordic Concrete Research Publication, Pulication No. 11: 162-171.

21. Life-365. (2013): Life-365 service life prediction model and Computer program for predicting the service life and life-cycle cost of reinforced concrete exposed to chlorides (Version 2.2): 50-53.

22. Chalee W., Jaturapitakkul C., Chindaprasirt P. (2009): Predicting the chloride penetration of fly ash concrete in seawater. Marine structures, 22(3), 341-353. doi:10.1016/j. marstruc.2008.12.001

23. Mangat P. S., Molloy B. T. (1994): Prediction of Long Term Chloride Concentration in Concrete. Materials and Structures, 27(170), 338-346. doi: 10.1007/BF02473426

24. Boddy A., Hooton R., Gruber K. (2001): Long-term testing of the chloride-penetration resistance of concrete containing high-reactivity metakaolin. Cement and Concrete Research, 31(5), 759-765. doi:10.1016/S0008-8846(01)00492-6

25. Thomas M. D. A., Bamforth P. B. (1999): Modelling chloride diffusion in concrete: Effect of fly ash and slag. Cement and Concrete Research, 29(4), 487-495. doi:10.1016/ S0008-8846(98)00192-6

26. Stanish K., Thomas M. (2003): The use of bulk diffusion tests to establish time-dependent concrete chloride diffusion coefficients. Cement and Concrete Research, 33(1), 55-62. doi:10.1016/S0008-8846(02)00925-0

27. Khatri R. P., Sirivivatnanon V. (2004): Characteristic service life for concrete exposed to marine environments.
Cement and Concrete Research, 34(5), 745-752. doi: 10.1016/S0008-8846(03)00086-3

28. Glass G., Buenfeld N. (1995): Chloride threshold levels for corrosion induced deterioration of steel in concrete. RILEM International Workshop on Chloride Penetration into Concrete, Saint-Rémy-lès-Chevreuse, France, 429-440. doi:10.1617/2912143454.043

29. Roque R., Kim N., Kim B., Lopp G. (2009): Durability of Fiber-Reinforced Concrete in Florida Environments. Florida, USA, p.255

30. Teruzzi T., Cadoni E., Frigeri G., Cangiano S., Plizzari G. A. (2004): Durability aspects of steel fibre reinforced concrete. in 6th RILEM Symposium on Fibre-Reinforced Cocnretes (FRC) - BEFIB2004, Varenna, Italy: 625-634.

31. Cadoni E., Cangiano S., Frigeri G., Plizzari G. A., Teruzzi T. (2005): On durability of Steel Fibre Reinforced Concrete. Construction Materials: Performances, Innovations and Structural implication, Thomas Telford, London, UK, 477486. doi: $10.1680 /$ ccfdc. 34013.0053

32. NT BUILD 443, (1995): Concrete, hardened: Accelerated chloride penetration. Nordtest, Esbo, Finland.

33. JTJ 270-98 (1998): Testing code of concrete for port and waterway engineering. Secondary Testing code of concrete for port and waterway engineering, Beijing, China, 202-205

34. Yuan Q., Shi C., De Schutter G., Audenaert K., Deng D. (2009): Chloride binding of cement-based materials subjected to external chloride environment - a review. Construction and Building Materials, 23, 1-13. doi: 10.1016/ j.conbuildmat.2008.02.004

35. Hoseini M., Bindiganavile V., Banthia N. (2009): The effect of mechanical stress on permeability of concrete: A review. Cement and Concrete Composites, 31, 213-220. doi:10.1016/j.cemconcomp.2009.02.003

36. Bamforth P. (1996): Predicting the risk of reinforcement corrosion in marine structures. Corrosion Prevention \& Control, 43, 91-100.

37. DuraCrete (2000): Probabilistic Performance based Durability Design of Concrete Structures, General Guidelines for Durability Design and Redesign, Document BE951347/R15. 